\title{
ПРОГНОЗ РАЗВИТИЯ ЗАБОЛЕВАЕМОСТИ КОРОНАВИРУСОМ В РЕСПУБЛИКЕ БЕЛАРУСЬ ВЕСНОЙ-ЛЕТОМ 2020 ГОДА. УТОЧНЕННЫЕ ДАННЫЕ.
}

\author{
П.С. Гринчук
}

Институт тепло- и массообмена имени А.В. Лыкова НАН Беларуси, г. Минск.

gps@hmti.ac.by

(30 апреля 2020 2.)

В данной работе на основании анализа статистических данных по заболеваемости коронавирусом в Республике Беларусь за период с 6 марта по 30 апреля 2020 г. выполнен уточненный прогнозный расчет динамики заболеваемости коронавирусом на территории Республики Беларусь. Согласно данному расчету пик заболеваемости может быть достигнут в период 28 апреля - 9 мая, когда прогнозируется ежедневно более 800 случаев заболевания. Расчет дает уточненную оценку в 44 тысячи заболевших коронавирусом в Республике Беларусь в период весны-лета 2020 г. Середина эпидемического процесса может быть преодолена в районе 9-10 мая, когда общее количество заболевших может достичь 22 тысяч. Уменьшение уровня заболеваемости до 100 новых случаев в день прогнозируется на период последней недели июня - начала июля. На краткосрочную перспективу в 30-50 дней точность прогноза по количеству заболевших оценивается в 10-15\%, по конкретным датам - плюс-минус 5-7 дней.

С момента составления первого прогноза [1] по динамике заболеваемости коронавирусом в Республике Беларусь прошло около недели. Появившиеся новые данные [2] не противоречат сделанному прогнозу, находятся в разумном согласовании с ним. Одновременно новые данные позволяют уточнить сделанный прогноз. В данном случае в качестве исходных данных для анализа будут использованы официальные статистические данные в период с 6 марта по 30 апреля 2020 г. [2] (рисунок 1).

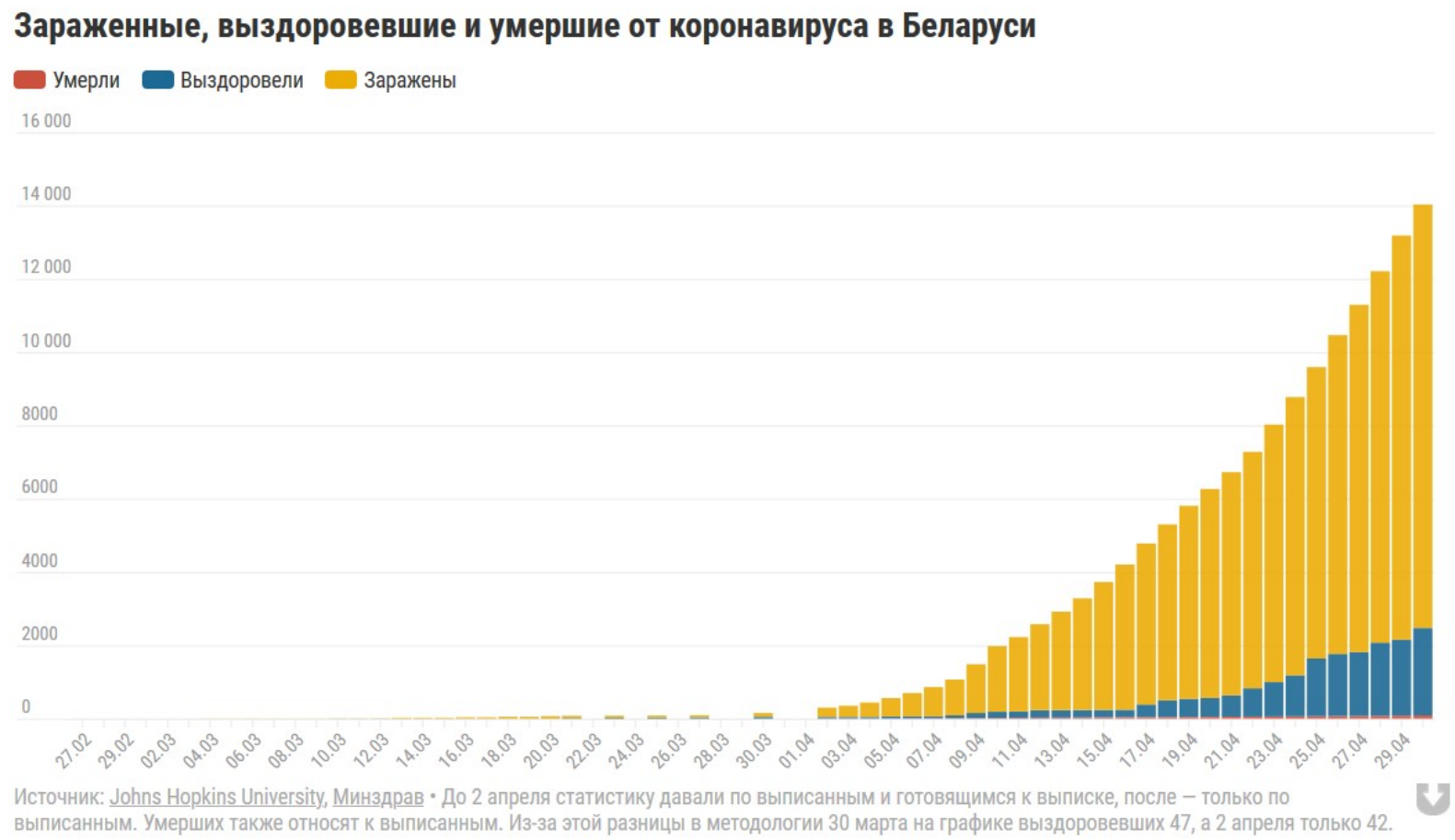

Рисунок 1. Данные по заболеваемости коронавирусом в Республике Беларусь по состоянию на 30 апреля 2020 [2]. 
В качестве инструмента математического анализа имеющихся данных, по-прежнему, будет использоваться подход, описанный в работе [3]. Уточненные коэффициенты $\alpha, \beta$ по новым данным (рисунок 2), имеют следующие числовые значения

$$
\alpha=1.72(4), \beta=0.949 \text {, }
$$

для выражения

$$
C(n+1)=\alpha[C(n)]^{\beta} .
$$

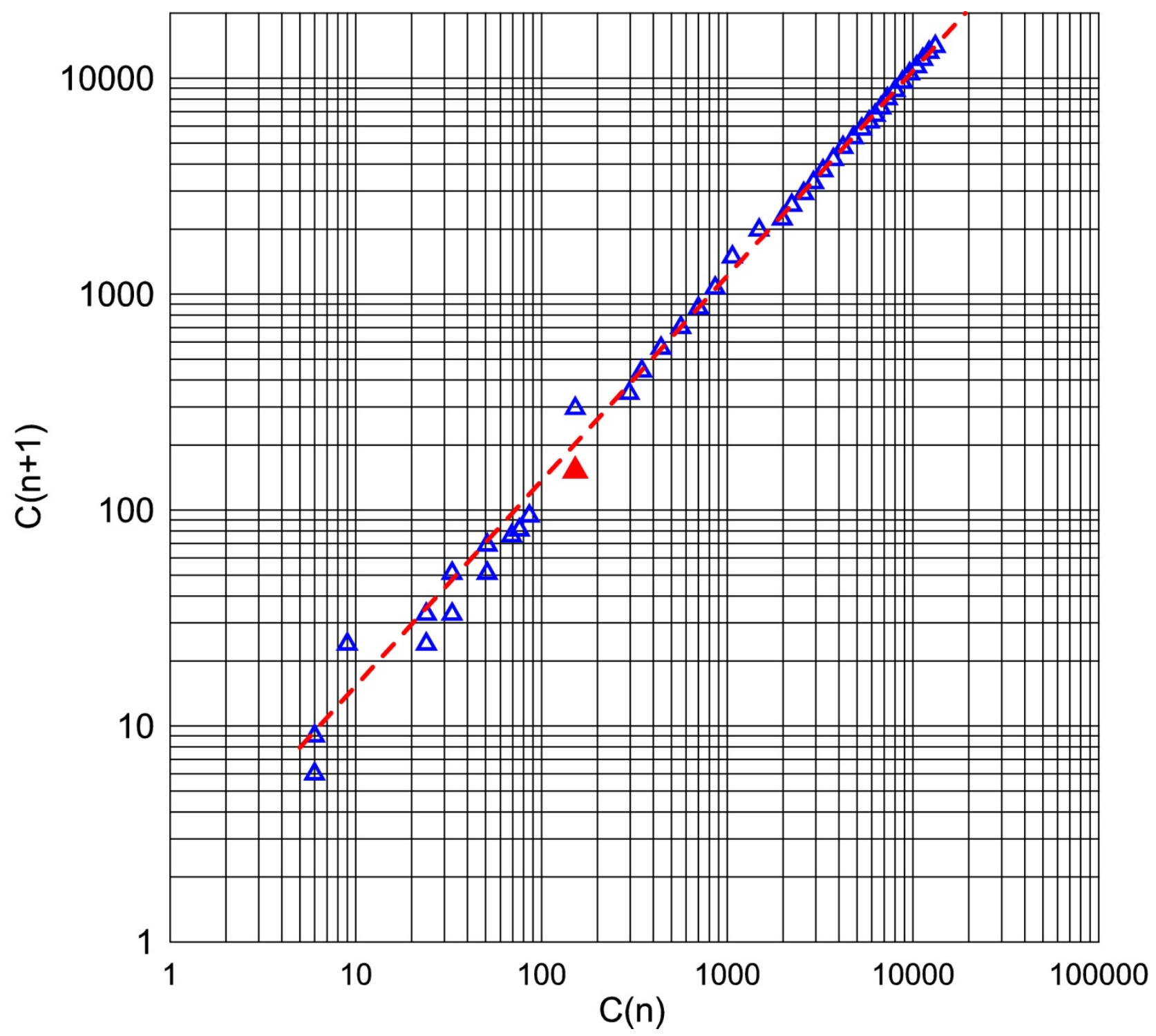

Рисунок 2. Уточненная зависимость количества вовлеченных в заболевание коронавирусом $\mathrm{C}(\mathrm{n}+1)$ в день $\mathrm{n}+1$ от количества вовлеченных в предыдущий день $\mathrm{C}(\mathrm{n})$ по статистическим данным заболеваемости коронавирусом в Республике Беларусь в период с 06 марта по 30 апреля 2020 г. [2]. Аппроксимация за период 30 марта (красный символ) - 30 апреля.

Еще раз отметим, что степенная зависимость вида (2) является не «случайным» совпадением, а связана с фрактальным характером самого процесса распространения эпидемии. Отличие показателя степенной зависимости $\beta$ от 1, по нашему мнению, отражает факт не $100 \%$ вероятности заражения коронавирусом при контакте здорового и заболевшего человека и случайный характер такого заражения, обусловленный рядом непредсказуемых факторов. Эту особенность можно объяснить и описать в рамках SIR - модели [4], с привлечением математического аппарата современной теории 
перколяции [5]. Но в данном случае задача является более прагматичной - получить конкретные прогнозные данные для конкретной страны.

Как и в работе [1], далее воспользуемся следующей функциональной зависимостью числа вовлеченных (заболевших) от времени, т.е. от количества дней n с начала отсчета [3]

$$
C(n)=\alpha^{\frac{1-\beta^{n}}{1-\beta}}[C(0)]^{\beta^{n}}
$$

Начальное значение количества вовлеченных $C(0)$, определенное по той же методике, что и в работе [1], остается прежним

$$
C(0)=100 \text {. }
$$

Результаты прогнозного расчета по функциональной зависимости (3) с параметрами (1), (4) представлены на рисунке 3 и в приложении. Для наглядности на этом рисунке пунктирными линиями показаны результаты предыдущего прогноза [1].

Анализируя уточненные данные, отметим следующее. Пик заболеваемости в данной работе рассматривается как максимальное количество новых случаев заражения коронавирусом в день. Прогноз по пику заболеваемости коронавирусом по уточненным данным не изменяется, но несколько расширяется. Этот пик приходится на период с 28 апреля по 9 мая (в предыдущем прогнозе с 28 апреля по 4 мая). При этом может регистрироваться более 800 случаев в день. Максимальное прогнозное количество заболевших, по уточненным данным, может достичь 44 тысяч человек. Середина (медиана) эпидемии по прогнозному расчету будет пройдена 9-10 мая, когда общее количество заболевших достигнет 50\% (около 22 тысяч заболевших) от общего прогнозного.

Достижение уровня заболеваемости в 100 новых случаев в день прогнозируется к 28 июня-3 июля; 10 случаев в день - к 15-20 августа. По рассматриваемым здесь прогнозным данным уровень в 97\% от всех заболевших может быть пройден 5-10 июля, 99 \% - 25-30 июля.

Отметим, что данные представленного здесь прогноза находятся в заметном противоречии с прогнозом, сделанным сингапурскими программистами [6], которые через несколько дней после появления своего первого прогноза радикально изменили его для ряда стран [7], а Республику Беларусь вообще исключили из своего прогноза [8] без объяснения каких-либо причин.

В заключении сделаем ряд важных замечаний относительно точности прогноза. Во-первых, прогнозный расчет опирается на официальные статистические данные и его точность напрямую зависит от точности этих исходных данных. Во-вторых, прогнозный расчет нельзя рассматривать как абсолютно точный. На взгляд автора, его задача уловить важные тенденции (рост, максимум, спад), дать для компетентных специалистов информацию о возможных количествах заболевших, что важно для планирования медицинских лечебных и профилактических мер. Относительную точность прогноза по количеству заболевших можно оценить в 10-15 \%, по датам наступления определенных событий в 5-7 дней, по крайней мере в первые 30-50 дней от даты составления прогноза. На более долгосрочную перспективу прогнозный расчет может указывать правильные тенденции, но к конкретным цифрам и датам в этом случае нужно относиться с определенной осторожностью и аккуратностью. Отметим также, что сделанный прогноз по причине специфики его методики справедлив до тех пор, пока условия развития процесса заболеваемости соответствуют условиям, при которых получены исходные статистические данные для прогноза. Так, усиление или послабление карантинных мероприятий может изменить ситуацию существенно. Например, весь апрель месяц, фактически, школьники страны находились на каникулах либо на дистанционном обучении. Изменение такого положения вещей может повлиять на ситуацию. Можно предположить, что изменение погодных условий (например, потепление), также в определенной мере изменит ситуацию. Так, для начального периода распространения заболевания 15 марта - 30 апреля погодные условия оставались приблизительно 
постоянными (среднесуточная температура $+5-+10{ }^{\circ} \mathrm{C}$, умеренная влажность). Однако заметное распространение заболевания в странах с более теплым климатом [9] свидетельствует, скорее, в пользу малого влияния температуры окружающей среды на данное заболевание.

В любом случае, выполненный прогноз фактически лишен фактора субъективности, который в большей или меньшей степени характерен даже для экспертных оценок врачей-эпидемиологов, непосредственно наблюдающих реальную ситуацию (при всем возможном уважении к нашим медикам, находящимся на переднем крае борьбы с заболеванием). Методика данного прогнозного расчета опубликована и достаточно прозрачна, исходные данные доступны. Любой желающий может повторить данный прогнозный расчет.

Отметим в заключении, что данная работа выполнена в порядке частной инициативы автора. 


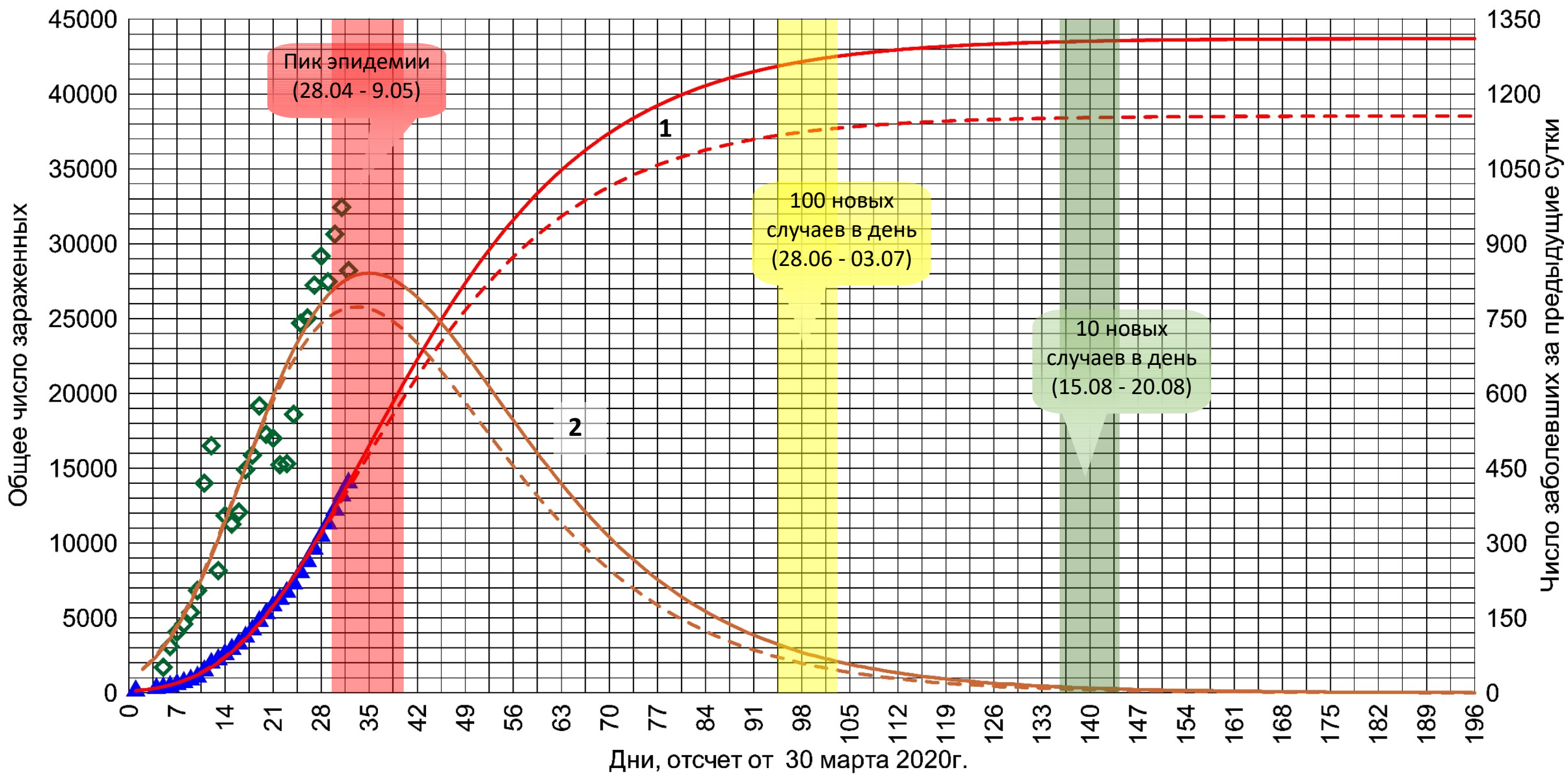

Рисунок 3. Результаты уточненного прогнозного расчета для общего количества заболевших коронавирусом в Республике Беларусь весной-летом 2020 г по данным на 30 апреля 2020 г. Кривая 1 (левая ось ординат) - прогнозный расчет для общего количества заболевших; синие символы - фактические данные; 2(правая ось ординат) - прогнозный расчет для количества вновь заболевших в данный день, зеленые символы - фактические данные. Пунктирная линия - результаты прогнозного расчета по данным от 24 апреля 2020 г. [1]. 
1. П.С. Гринчук. Прогноз развития заболеваемости коронавирусом в Республике Беларусь. Препринт от 26.04.2020 г. DOI: http://dx.doi.org/10.24108/preprints-3112033

2. Последняя информация о коронавирусе в Беларуси и мире (URL https://news.tut.by/coronavirus$\underline{\operatorname{map} /)}$

3. Fanelli D., Piazza F. Analysis and forecast of COVID-19 spreading in China, Italy and France // Chaos, Solitons \& Fractals. 2020. V. 134. Art. \# 109761.

4. Pastor-Satorras R. et al. Epidemic processes in complex networks // Reviews of Modern Physics. 2015. V. 87. Iss. 3. Pp. 925-979.

5. P. S. Grinchuk. Cluster size distribution in percolation theory and fractal Cantor dust // Physical Review E. 2007. V. 75. Iss. 4. Art. \# 041118.

6. Сингапурские аналитики спрогнозировали дату окончания пандемии коронавируса в Беларуси. Газета «Наша ніва». Статья от 27.04.2020. URL https://nn.by/?c=ar\&i=250789\&lang=ru

7. Ученые, предсказавшие окончание вспышки COVID-19 в России, радикально изменили свой прогноз. Новостной сайт РосБалт. Новость от 28.04.2020 г.

URL https://www.rosbalt.ru/world/2020/04/28/1840918.html?noredir=true

8. When Will COVID-19 End Data-Driven Estimation of End Dates (updated on April 30). URL https://ddi.sutd.edu.sg/.

9. COVID-19 Dashboard by the Center for Systems Science and Engineering (CSSE) at Johns Hopkins University (JHU)

https://www.arcgis.com/apps/opsdashboard/index.htm|\#/bda7594740fd40299423467b48e9ecf6 
Приложение. Результаты прогнозного расчета заболеваемости коронавирусом в Республике Беларусь в период весны-лета 2020 г. по уточненным данным от 30 апреля 2020 г [2]. Точность прогнозного расчета оценивается в 10-15\%.

\begin{tabular}{|c|c|c|c|c|c|}
\hline Дата & $\begin{array}{c}\text { День с начала } \\
\text { отсчета }\end{array}$ & $\begin{array}{c}\text { Прогнозное } \\
\text { число } \\
\text { вовлеченных } \\
\text { (заболевших) }\end{array}$ & $\begin{array}{c}\text { Фактическое } \\
\text { число } \\
\text { заболевших }\end{array}$ & $\begin{array}{c}\text { Количество } \\
\text { заболевших за } \\
\text { день, прогноз }\end{array}$ & $\begin{array}{c}\text { Количество } \\
\text { заболевших за } \\
\text { день, факт }\end{array}$ \\
\hline 1 & 2 & 3 & 4 & 5 & 6 \\
\hline 30 мар & 1 & 136 & 152 & & \\
\hline 31 мар & 2 & 183 & & 47 & \\
\hline 01 апр & 3 & 242 & & 59 & \\
\hline 02 апр & 4 & 315 & 296 & 73 & \\
\hline 03 апр & 5 & 406 & 347 & 90 & 51 \\
\hline 04 апр & 6 & 515 & 440 & 109 & 93 \\
\hline 05 апр & 7 & 646 & 562 & 131 & 122 \\
\hline 06 апр & 8 & 801 & 700 & 155 & 138 \\
\hline 07 апр & 9 & 982 & 861 & 181 & 161 \\
\hline 08 апр & 10 & 1192 & 1066 & 210 & 205 \\
\hline 09 апр & 11 & 1432 & 1486 & 240 & 420 \\
\hline 10 апр & 12 & 1704 & 1981 & 273 & 495 \\
\hline 11 апр & 13 & 2011 & 2226 & 307 & 245 \\
\hline 12 апр & 14 & 2353 & 2581 & 342 & 355 \\
\hline 13 апр & 15 & 2731 & 2919 & 378 & 338 \\
\hline 14 апр & 16 & 3146 & 3281 & 415 & 362 \\
\hline 15 апр & 17 & 3598 & 3728 & 452 & 447 \\
\hline 16 апр & 18 & 4086 & 4204 & 489 & 476 \\
\hline 17 апр & 19 & 4611 & 4779 & 525 & 575 \\
\hline 18 апр & 20 & 5172 & 5297 & 560 & 518 \\
\hline 19 апр & 21 & 5767 & 5807 & 595 & 510 \\
\hline 20 апр & 22 & 6394 & 6264 & 627 & 457 \\
\hline 21 апр & 23 & 7053 & 6723 & 659 & 459 \\
\hline 22 апр & 24 & 7740 & 7281 & 688 & 558 \\
\hline 23 апр & 25 & 8454 & 8022 & 714 & 741 \\
\hline 24 апр & 26 & 9193 & 8773 & 739 & 751 \\
\hline 25 апр & 27 & 9954 & 9590 & 761 & 817 \\
\hline 26 апр & 28 & 10734 & 10465 & 780 & 875 \\
\hline 27 апр & 29 & 11531 & 11289 & 797 & 824 \\
\hline 28 апр & 30 & 12342 & 12208 & 811 & 919 \\
\hline 29 апр & 31 & 13164 & 13181 & 822 & 973 \\
\hline 30 апр & 32 & 13994 & 14027 & 831 & 846 \\
\hline 01 май & 33 & 14831 & & 837 & \\
\hline 02 май & 34 & 15671 & & 840 & \\
\hline 03 май & 35 & 16513 & & 841 & \\
\hline 04 май & 36 & 17353 & & 840 & \\
\hline 05 май & 37 & 18190 & & 837 & \\
\hline 06 май & 38 & 19022 & & 832 & \\
\hline 07 май & 39 & 19846 & & 824 & \\
\hline
\end{tabular}




\begin{tabular}{|c|c|c|c|c|c|}
\hline 1 & 2 & 3 & 4 & 5 & 6 \\
\hline 08 май & 40 & 20661 & & 815 & \\
\hline 09 май & 41 & 21466 & & 805 & \\
\hline 10 май & 42 & 22259 & & 793 & \\
\hline 11 май & 43 & 23038 & & 779 & \\
\hline 12 май & 44 & 23802 & & 765 & \\
\hline 13 май & 45 & 24551 & & 749 & \\
\hline 14 май & 46 & 25284 & & 733 & \\
\hline 15 май & 47 & 26000 & & 716 & \\
\hline 16 май & 48 & 26698 & & 698 & \\
\hline 17 май & 49 & 27377 & & 679 & \\
\hline 18 май & 50 & 28038 & & 661 & \\
\hline 19 май & 51 & 28680 & & 642 & \\
\hline 20 май & 52 & 29302 & & 623 & \\
\hline 21 май & 53 & 29906 & & 603 & \\
\hline 22 май & 54 & 30490 & & 584 & \\
\hline 23 май & 55 & 31055 & & 565 & \\
\hline 24 май & 56 & 31601 & & 546 & \\
\hline 25 май & 57 & 32128 & & 527 & \\
\hline 26 май & 58 & 32636 & & 508 & \\
\hline 27 май & 59 & 33125 & & 490 & \\
\hline 28 май & 60 & 33597 & & 471 & \\
\hline 29 май & 61 & 34050 & & 454 & \\
\hline 30 май & 62 & 34486 & & 436 & \\
\hline 31 май & 63 & 34905 & & 419 & \\
\hline 01 июн & 64 & 35308 & & 402 & \\
\hline 02 июн & 65 & 35694 & & 386 & \\
\hline 03 июн & 66 & 36064 & & 370 & \\
\hline 04 июн & 67 & 36419 & & 355 & \\
\hline 05 июн & 68 & 36760 & & 340 & \\
\hline 06 июн & 69 & 37085 & & 326 & \\
\hline 07 июн & 70 & 37397 & & 312 & \\
\hline 08 июн & 71 & 37695 & & 298 & \\
\hline 09 июн & 72 & 37981 & & 285 & \\
\hline 10 июн & 73 & 38253 & & 273 & \\
\hline 11 июн & 74 & 38514 & & 261 & \\
\hline 12 июн & 75 & 38763 & & 249 & \\
\hline 13 июн & 76 & 39001 & & 238 & \\
\hline 14 июн & 77 & 39228 & & 227 & \\
\hline 15 июн & 78 & 39444 & & 217 & \\
\hline 16 июн & 79 & 39651 & & 207 & \\
\hline 17 июн & 80 & 39848 & & 197 & \\
\hline 18 июн & 81 & 40036 & & 188 & \\
\hline 19 июн & 82 & 40216 & & 179 & \\
\hline 20 июн & 83 & 40386 & & 171 & \\
\hline 21 июн & 84 & 40549 & & 163 & \\
\hline 22 июн & 85 & 40704 & & 155 & \\
\hline 23 июн & 86 & 40852 & & 148 & \\
\hline
\end{tabular}




\begin{tabular}{|c|c|c|c|c|c|}
\hline 1 & 2 & 3 & 4 & 5 & 6 \\
\hline 24 июн & 87 & 40993 & & 141 & \\
\hline 25 июн & 88 & 41127 & & 134 & \\
\hline 26 июн & 89 & 41254 & & 128 & \\
\hline 27 июн & 90 & 41376 & & 121 & \\
\hline 28 июн & 91 & 41491 & & 116 & \\
\hline 29 июн & 92 & 41601 & & 110 & \\
\hline 30 июн & 93 & 41706 & & 105 & \\
\hline 01 июл & 94 & 41805 & & 100 & \\
\hline 02 июл & 95 & 41900 & & 95 & \\
\hline 03 июл & 96 & 41990 & & 90 & \\
\hline 04 июл & 97 & 42076 & & 86 & \\
\hline 05 июл & 98 & 42157 & & 81 & \\
\hline 06 июл & 99 & 42235 & & 77 & \\
\hline 07 июл & 100 & 42308 & & 74 & \\
\hline 08 июл & 101 & 42378 & & 70 & \\
\hline 09 июл & 102 & 42445 & & 67 & \\
\hline 10 июл & 103 & 42508 & & 63 & \\
\hline 11 июл & 104 & 42568 & & 60 & \\
\hline 12 июл & 105 & 42625 & & 57 & \\
\hline 13 июл & 106 & 42679 & & 54 & \\
\hline 14 июл & 107 & 42731 & & 52 & \\
\hline 15 июл & 108 & 42780 & & 49 & \\
\hline 16 июл & 109 & 42826 & & 47 & \\
\hline 17 июл & 110 & 42871 & & 44 & \\
\hline 18 июл & 111 & 42913 & & 42 & \\
\hline 19 июл & 112 & 42952 & & 40 & \\
\hline 20 июл & 113 & 42990 & & 38 & \\
\hline 21 июл & 114 & 43026 & & 36 & \\
\hline 22 июл & 115 & 43060 & & 34 & \\
\hline 23 июл & 116 & 43093 & & 32 & \\
\hline 24 июл & 117 & 43124 & & 31 & \\
\hline 25 июл & 118 & 43153 & & 29 & \\
\hline 26 июл & 119 & 43181 & & 28 & \\
\hline 27 июл & 120 & 43207 & & 26 & \\
\hline 28 июл & 121 & 43232 & & 25 & \\
\hline 29 июл & 122 & 43256 & & 24 & \\
\hline 30 июл & 123 & 43279 & & 23 & \\
\hline 31 июл & 124 & 43300 & & 21 & \\
\hline 01 авг & 125 & 43321 & & 20 & \\
\hline 02 авг & 126 & 43340 & & 19 & \\
\hline $03 \mathrm{aвг}$ & 127 & 43358 & & 18 & \\
\hline 04 авг & 128 & 43376 & & 17 & \\
\hline 05 авг & 129 & 43392 & & 17 & \\
\hline $06 \mathrm{aвr}$ & 130 & 43408 & & 16 & \\
\hline 07 авг & 131 & 43423 & & 15 & \\
\hline $08 \mathrm{aвг}$ & 132 & 43437 & & 14 & \\
\hline 09 авг & 133 & 43450 & & 13 & \\
\hline
\end{tabular}




\begin{tabular}{|c|c|c|c|c|c|}
\hline 1 & 2 & 3 & 4 & 5 & 6 \\
\hline 10 авг & 134 & 43463 & & 13 & \\
\hline 11 авг & 135 & 43475 & & 12 & \\
\hline 12 авг & 136 & 43487 & & 12 & \\
\hline 13 авг & 137 & 43498 & & 11 & \\
\hline 14 авг & 138 & 43508 & & 10 & \\
\hline 15 авг & 139 & 43518 & & 10 & \\
\hline 16 авг & 140 & 43527 & & 9 & \\
\hline 17 авг & 141 & 43536 & & 9 & \\
\hline 18 авг & 142 & 43545 & & 8 & \\
\hline 19 авг & 143 & 43553 & & 8 & \\
\hline 20 авг & 144 & 43560 & & 8 & \\
\hline 21 авг & 145 & 43567 & & 7 & \\
\hline 22 авг & 146 & 43574 & & 7 & \\
\hline $23 \mathrm{aвr}$ & 147 & 43581 & & 6 & \\
\hline 24 авг & 148 & 43587 & & 6 & \\
\hline $25 \mathrm{aвr}$ & 149 & 43593 & & 6 & \\
\hline 26 авг & 150 & 43598 & & 6 & \\
\hline 27 авг & 151 & 43603 & & 5 & \\
\hline $28 \mathrm{aвr}$ & 152 & 43608 & & 5 & \\
\hline 29 авг & 153 & 43613 & & 5 & \\
\hline 30 авг & 154 & 43618 & & 4 & \\
\hline $31 \mathrm{aBr}$ & 155 & 43622 & & 4 & \\
\hline $01 \mathrm{ceн}$ & 156 & 43626 & & 4 & \\
\hline $02 \mathrm{ceн}$ & 157 & 43630 & & 4 & \\
\hline 03 сен & 158 & 43633 & & 4 & \\
\hline 04 сен & 159 & 43637 & & 3 & \\
\hline 05 сен & 160 & 43640 & & 3 & \\
\hline 06 сен & 161 & 43643 & & 3 & \\
\hline $07 \mathrm{ceH}$ & 162 & 43646 & & 3 & \\
\hline 08 сен & 163 & 43649 & & 3 & \\
\hline 09 сен & 164 & 43652 & & 3 & \\
\hline $10 \mathrm{cен}$ & 165 & 43654 & & 3 & \\
\hline $11 \mathrm{ceн}$ & 166 & 43657 & & 2 & \\
\hline $12 \mathrm{cен}$ & 167 & 43659 & & 2 & \\
\hline $13 \mathrm{cен}$ & 168 & 43661 & & 2 & \\
\hline $14 \mathrm{ceH}$ & 169 & 43663 & & 2 & \\
\hline $15 \mathrm{ceн}$ & 170 & 43665 & & 2 & \\
\hline $16 \mathrm{ceн}$ & 171 & 43667 & & 2 & \\
\hline $17 \mathrm{cен}$ & 172 & 43669 & & 2 & \\
\hline $18 \mathrm{ceH}$ & 173 & 43670 & & 2 & \\
\hline $19 \mathrm{ceн}$ & 174 & 43672 & & 2 & \\
\hline $20 \mathrm{cен}$ & 175 & 43673 & & 1 & \\
\hline $21 \mathrm{cен}$ & 176 & 43675 & & 1 & \\
\hline 22 сен & 177 & 43676 & & 1 & \\
\hline 23 сен & 178 & 43678 & & 1 & \\
\hline $24 \mathrm{ceH}$ & 179 & 43679 & & 1 & \\
\hline $25 \mathrm{ceH}$ & 180 & 43680 & & 1 & \\
\hline
\end{tabular}




\begin{tabular}{|c|c|c|c|c|c|}
\hline 1 & 2 & 3 & 4 & 5 & 6 \\
\hline 26 сен & 181 & 43681 & & 1 & \\
\hline 27 сен & 182 & 43682 & & 1 & \\
\hline 28 сен & 183 & 43683 & & 1 & \\
\hline 29 сен & 184 & 43684 & & 1 & \\
\hline 30 сен & 185 & 43685 & & 1 & \\
\hline 01 окт & 186 & 43686 & & 1 & \\
\hline 02 окт & 187 & 43686 & & 1 & \\
\hline 03 окт & 188 & 43687 & & 1 & \\
\hline 04 окт & 189 & 43688 & & 1 & \\
\hline 05 окт & 190 & 43689 & & 1 & \\
\hline 06 окт & 191 & 43689 & & 1 & \\
\hline 07 окт & 192 & 43690 & & 1 & \\
\hline 08 окт & 193 & 43691 & & 1 & \\
\hline 09 окт & 194 & 43691 & & 1 & \\
\hline 10 окт & 195 & 43692 & & 1 & \\
\hline 11 окт & 196 & 43692 & & 0 & \\
\hline
\end{tabular}

